\title{
Influence of cut-out hole on multi-layer Kevlar-29/epoxy composite laminated plates
}

\begin{abstract}
This paper presented the effect of cutout hole on multi layer of Kevlar-29/epoxy composite laminated plates this effect occurred and fiber orientation angle. An experimental procedure was developed to study the performance of these effects under quasi-static compressive and tensile load using a servo-hydraulic testing machine. The work involved investigation on the variety of orientation angles of Kevlar-29 fiber. The ultimate load of failure for each Kevlar29/epoxy laminated plates had been determined and specified the optimum angle orientation and the load reduction due to the effect of fiber orientation angle $\left(+45^{\circ} /-45^{\circ}\right)$ was low in the case for compared $\left(0^{\circ} / 90^{\circ}\right)$ orientation angle of fiber. To simulate this problem the researcher used Explicit Mesh for AUTODYN under ANSYS-12.1 software, where the researcher found that the results obtained via this simulation agreed reasonably well with the experimental results and the maximum difference between the experimental conditions and the simulation was $5.8 \%$.
\end{abstract}

Keyword: Cut-out; Kevlar-29/epoxy composite; Multi-layer 